\title{
Studies on the Detoxicating Hormone of the Liver (Yakriton).
}

57th Report.

Effect of Yakriton on Hypoglycemic Action of Insulin.

Preliminary Report. Influence of Different Intervals between Yakriton and Insulin Administrations.

By

Akira Takamatsu and Yoshitaka Uga.

（高烃昆） (宇贺義孝)

(From the Pediatric Department, Faculty of Medicine, Tohoku

Imperial University, Sendai. Director: Prof. A. Sato.)

\section{Introduction.}

Concerning the relationship between the blood sugar content and liver, Fis her ${ }^{1)}$ in 1925 declared that to regulate the amount of blood sugar was the most important one of the functions of the liver in the line of carbohydrate metabolism. Prof. A. S ato ${ }^{29}$ also made a report that yakriton, the detoxicating hormone of the liver, acted antihyperglycemic not through a blood sugar lowering property but through its ability to keep the normal level of the blood sugar, on the basis of Asakura and Sakurada's ${ }^{33}$ experiment that yakriton acted strongly against hyperglycemia due to the subcutaneous administration of hypertonic glucose solution. With the foregoing in view we have undertaken to investigate the relationship between such an effect of yakriton and the hypoglycemic action of insulin.

In the present paper we desire to report on the relation between the hypoglycemic action of insulin and the effect of yakriton in 4 and 8R.A.U.* only, because the relationship in question seems to be rather complicated.

1) F. Fischer, Physiologie und Pathologie der Leber, 1925, 65.

2) A. S a to, Tohoku J. Exp. Med., 1929, 13, 502.

3) K. A s a u ra and H. S a kurad a, Tohoku J. Exp. Med., 1929, 13, 450.

* R.A.U. Rabbit-Ammonia-Units. 


\section{Method of Experiment.}

Healthy rabbits were used as experimental animals. They were subjected to a fast of 24 hours. After this period yakriton was administered subcutaneously in an amount of 4 R.A.U.* in one series and 8 R.A.U. in another series of experiments, then insulin Toronto was administered intravenously in an amount of 0.1 c.c. (one unit)** per kilo of body weight and the variation of blood sugar was observed. Yakriton was used in one series simultaneously with insulin and in another series $1,2,3,4$, or 5 hours previous to the use of insulin. Of course a control experiment with insulin in the same dosis was performed one week previous to the experiment proper with yakriton and insulin in one and the same animals. The blood sugar curve obtained in the experiment proper was compared with that obtained in the control, i. e. with the curve of insulin hypoglycemia. Besides, healthy rabbits were beforehand classified according to Sato and Sakurada's ${ }^{4)}$ liver function test, and only $b$ and $f$-classed animals were used for the experiment. So we were able to observe not only the influence of yakriton upon insulin hypoglycemia, but also the course of insulin-hypoglycemia itself in both $b$ and $f$ classed animals. Through all these experiments blood was taken from ear veins and the method used for sugar was that of $\mathrm{Hagedorn}$ and Jensen.5)

\section{Results of Experimentation.}

It will be seen that the degree of the effect of yakriton to inhibit the hypoglycemic action of insulin is variable according to the interval between the administration of yakriton and that of insulin. As in the cases of No. 4 in Tables II and IV, yakriton shows the greatest inhibiting effect upon the hypoglycemic action of the latter, when it is administered 3 hours previous to the use of insulin. In these cases the reduction of blood sugar figures was very small as is clearly seen from Fig. 1 and Fig. 2. But such a reduction will still be seen in No. 6 in Table II and No. 6 in Table III; in which cases yakriton was administered 5 hours previous to insulin. And some reduction will be manifest even in the case of No. 1 in Tables I, II, III, and IV, where

* The preparation of emulsified yakriton used contained 1 R.A.U. per 1 c.c.

** 0.1 c.c. of insulin Toronto used contained one unit.

4) A. S a to and H. S a kurad a, Tohoku J. Exp. Med., 1927, 8, 347.

5) Hagedorn H. C. and Jensen, B. N., Bioch. Zeitschr., 1923, 135, 46. 
TABLE I.

Effect of yakriton on hypoglycemic action of insulin.

Effeet of 4 R.A.U. in the case of b-classed animals.

\begin{tabular}{|c|c|c|c|c|c|c|c|c|c|c|c|c|c|c|}
\hline \multirow{2}{*}{ 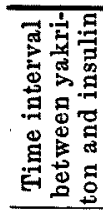 } & \multirow{2}{*}{ 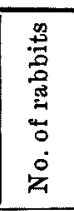 } & \multirow{2}{*}{ 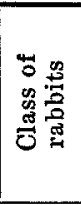 } & \multirow{2}{*}{ 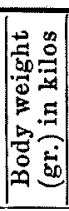 } & \multirow{2}{*}{ 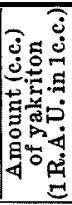 } & \multirow{2}{*}{ 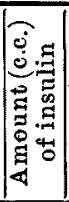 } & \multicolumn{7}{|c|}{ Blood sugar in Per cent } & \multirow{2}{*}{ 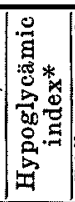 } & \multirow{2}{*}{ 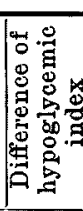 } \\
\hline & & & & & & 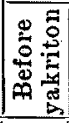 & 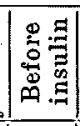 & $\underset{\sim}{\stackrel{0}{9}}$ & $\stackrel{\Xi}{\Xi}$ & 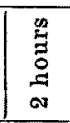 & 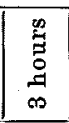 & 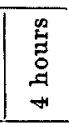 & & \\
\hline bo & & & & 7.8 & $\begin{array}{l}19 \\
20\end{array}$ & & & & & & & & & \\
\hline & & & $\begin{array}{l}2.45 \\
2.36\end{array}$ & $\overline{9.5}$ & $\begin{array}{l}0.25 \\
0.23\end{array}$ & $\overline{\overline{103}}$ & & & & & & & 41 & \\
\hline & No & R-b & 1.92 & $\frac{-10}{7.6}$ & $\begin{array}{l}0.19 \\
0.19\end{array}$ & $\overline{103}$ & & & & & & & 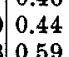 & 0.15 \\
\hline & & & $\begin{array}{l}1.90 \\
1.87 \\
1.97\end{array}$ & $\frac{7.6}{76}$ & & 3 & & & & & & & 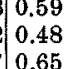 & 0.17 \\
\hline & & & 2.60 & $\frac{\overline{0}}{10.0}$ & $\begin{array}{l}26 \\
25\end{array}$ & $\frac{}{117}$ & & & & & & & 0.42 & 4 \\
\hline & $\begin{array}{l}\text { No.6 } \\
(4356)\end{array}$ & $\underset{(\mathrm{cb}}{\mathrm{R}}$ & $\begin{array}{l}2.50 \\
2.64\end{array}$ & $1 \overline{10.5}$ & 0.25 & & & & & & & & $\begin{array}{l}0.46 \\
0.46\end{array}$ & 00 \\
\hline
\end{tabular}

TABLE III.

Effect of yakriton on hypo-glycemic action of insulin.

Effect of 4 R.A.U. in the case of f-classed animals.

\begin{tabular}{|c|c|c|c|c|c|c|c|c|c|c|c|c|c|c|}
\hline \multirow{2}{*}{ 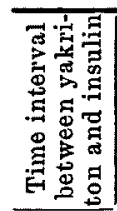 } & \multirow{2}{*}{ 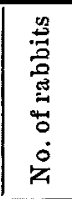 } & \multirow{2}{*}{ 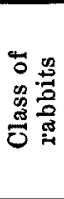 } & \multirow{2}{*}{ 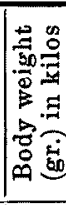 } & \multirow{2}{*}{ 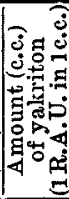 } & \multirow{2}{*}{ 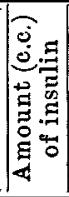 } & \multicolumn{7}{|c|}{ Blood sugar in Per cent } & \multirow{2}{*}{ 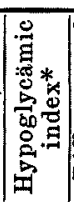 } & \multirow{2}{*}{ 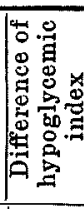 } \\
\hline & & & & & & 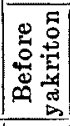 & 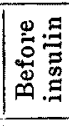 & $\underset{-\infty}{\Xi}$ & 鴶 & $\frac{\stackrel{\infty}{0}}{\stackrel{0}{0}}$ & 昜 & $\begin{array}{l}\infty \\
\stackrel{\infty}{0} \\
\stackrel{0}{0} \\
+ \\
+1\end{array}$ & & \\
\hline bo & & & & 7.6 & $\begin{array}{l}0.19 \\
0.19\end{array}$ & & & & & & & & & 0.09 \\
\hline hou & $\left(\begin{array}{c}\text { No. } \\
(4358)\end{array}\right)$ & & & $\frac{0}{8.4}$ & $\begin{array}{l}0.22 \\
0.21\end{array}$ & & & & & & & 78 & 0.41 & 0.14 \\
\hline & $\left(\begin{array}{c}\text { No. } 3 \\
(4359)\end{array}\right.$ & $\begin{array}{l}\mathrm{R-f} \\
\text { (fof) }\end{array}$ & $\begin{array}{l}1.90 \\
2.00\end{array}$ & $\frac{1}{8.0}$ & $\begin{array}{l}0.19 \\
0.20\end{array}$ & & & & & & & $\mid \begin{array}{l}0.093 \\
0.095\end{array}$ & $\begin{array}{l}0.41 \\
0.62\end{array}$ & 21 \\
\hline & $\left(\begin{array}{l}\text { No. } 4 \\
(1)\end{array}\right)$ & $\begin{array}{l}R-f \\
\text { (cff) }\end{array}$ & $\begin{array}{l}1.85 \\
1.85\end{array}$ & $\frac{7}{7.4}$ & $\begin{array}{l}0.19 \\
0.19\end{array}$ & & & & & & 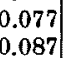 & & $\begin{array}{l}0.42 \\
0.70\end{array}$ & 0.28 \\
\hline & $\left(\begin{array}{l}\text { No.5 } \\
(4361)\end{array}\right.$ & $\begin{array}{l}\mathrm{R}-\mathrm{f} \\
\text { (fff) }\end{array}$ & 2.10 & $\overline{8.0}$ & $\begin{array}{l}0.21 \\
0.20\end{array}$ & & 0. & & & 0.0 & & & $\begin{array}{l}0.45 \\
0.52\end{array}$ & 7 \\
\hline & $\left(\begin{array}{l}\text { No. } 6 \\
(4362)\end{array}\right)$ & $\underset{\text { (fff) }}{R-f}$ & $\begin{array}{l}1.75 \\
1.85\end{array}$ & $\frac{7}{7.4}$ & 0.18 & & & & & & & & $\mid \begin{array}{l}0.44 \\
0.52\end{array}$ & 8 \\
\hline
\end{tabular}

yakriton and insulin were used simultaneously. In other words, yakriton counteracts the hypoglycemic action of insulin, but the intensity of this insulin inhibiting action of the hormone depends on the length of interval between the use of yakriton and of insulin on one

* Cf. Footnote, p. 528.

$\S$ Serial number of rabbit. 
TABLE III.

Effect of yakriton on hypoglycemic action of insulin.

Effect of 8 R.A.U. in the case of b-classed animals.

\begin{tabular}{|c|c|c|c|c|c|c|c|c|c|c|c|c|c|c|}
\hline \multirow{2}{*}{ 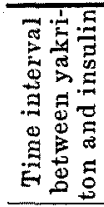 } & \multirow{2}{*}{ 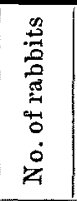 } & \multirow{2}{*}{ 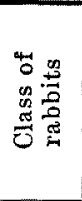 } & \multirow{2}{*}{ 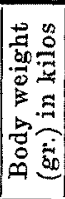 } & \multirow{2}{*}{ 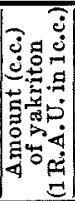 } & \multirow{2}{*}{ 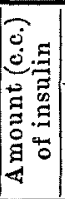 } & \multicolumn{7}{|c|}{ Blood sugar in Per cent } & \multirow{2}{*}{ 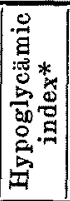 } & \multirow{2}{*}{ 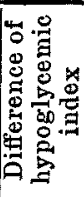 } \\
\hline & & & & & & 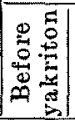 & 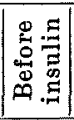 & 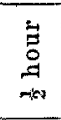 & $\begin{array}{l}E \\
0 \\
0 \\
\Xi \\
-1\end{array}$ & 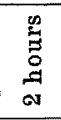 & $\begin{array}{l}\infty \\
\stackrel{\infty}{\Xi} \\
\stackrel{9}{9} \\
\infty\end{array}$ & 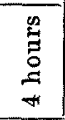 & & \\
\hline \multirow{2}{*}{0 hour } & No. & & 11 & - & 0.21 & - & & & & & & & 0.40 & 0.02 \\
\hline & $(4.363)$ & $\begin{array}{c}(\mathrm{bbc}) \\
\mathrm{R} \cdot \mathrm{b}\end{array}$ & $\begin{array}{l}2.07 \\
2.37\end{array}$ & 16.0 & $\begin{array}{l}0.20 \\
0.24\end{array}$ & 0.107 & & & 30.0 & y. & 0 & 096 & $\begin{array}{l}0.42 \\
0.38\end{array}$ & \multirow[b]{2}{*}{0.05} \\
\hline 1 hour & $(4364)$ & $(\mathrm{bbb})$ & 2.40 & 19.2 & 0.24 & 0.106 & 0 . & 0 & 0 & 0.05 & .10 & .107 & 0.43 & \\
\hline \multirow{2}{*}{2 hours } & No.3] & $\mathrm{R}-1$ & 2.49 & - & 0.25 & -10 & 0. & 0. & 0 & 0.06 & 0.09 & 108 & 0.53 & \multirow{2}{*}{0.14} \\
\hline & $(4365)$ & (bcb) & 2.53 & 20.0 & 0,25 & 0.103 & 0. & 0.068 & 0 & 0.09 & 0.115 & .115 & 0.67 & \\
\hline \multirow{2}{*}{3 hours } & No.4] & $\mathbf{R}-\mathbf{1}$ & 1.98 & 一 & 0.20 & $-c$ & $0.102 \mid$ & 0.062 & 0.0 & 0.04 & 0.07 & 0.096 & 0.44 & \multirow{2}{*}{0.22} \\
\hline & $(4366)$ & $(\mathrm{bbb})$ & 1.98 & 16.0 & 0.20 & 0.097 & 0.102 & 0.073 & 0.06 & 0.085 & 0.094 & 0.117 & 0.66 & \\
\hline \multirow{2}{*}{4 hours } & No.5 & $R \cdot b$ & 2.22 & 一 & 0.22 & -6 & 0.104 & 0.057 & 0.05 & 0.062 & 0.069 & 0.083 & 0.48 & \multirow{2}{*}{0.16} \\
\hline & $(4367$ & (bcb) & 1.75 & 18.0 & 0.18 & 0.111 & $0.094 \mid$ & 0.060 & 0.068 & 0.071 & 0.072 & 0.098 & 0.64 & \\
\hline \multirow{2}{*}{5 hours } & No.6 & $\mathbf{R}$ & 2.22 & - & 0.22 & $=10$ & 0.111 & 0.057 & 0.042 & 0.06 & 0.072 & 0.107 & 0.38 & \multirow{2}{*}{0.17} \\
\hline & $(4368)$ & & 2.24 & 18.0 & 0.22 & $104 \mid c$ & $|0.101|$ & 0.064 & 0.056 & 0.081 & 0.098 & 0.102 & 0.55 & \\
\hline
\end{tabular}

TABLE IV.

Effect of yalkiton on hypoglycemic action of insulin.

Effect of 8 R.A.U. in the case of f-classed animals.

\begin{tabular}{|c|c|c|c|c|c|c|c|c|c|c|c|c|c|c|}
\hline \multirow{2}{*}{ 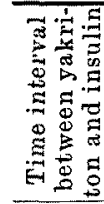 } & \multirow{2}{*}{ 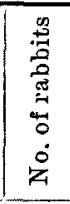 } & \multirow{2}{*}{ 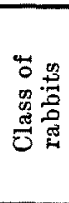 } & \multirow{2}{*}{ 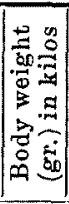 } & \multirow{2}{*}{\multicolumn{2}{|c|}{ 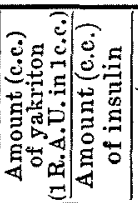 }} & \multicolumn{7}{|c|}{ Blood sugar in Per cent } & \multirow{2}{*}{ 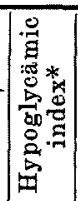 } & \multirow{2}{*}{ 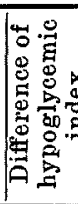 } \\
\hline & & & & & & 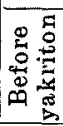 & 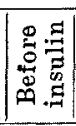 & $\stackrel{3}{\Xi}$ & $\stackrel{\Xi}{\Xi}$ & $\underset{\infty}{\stackrel{\infty}{\Xi}}$ & $\underset{\infty}{\stackrel{\infty}{0}}$ & 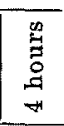 & & \\
\hline & $\begin{array}{l}\text { No.1 } \\
(4369)\end{array}$ & & & & $\mid \begin{array}{l}0.20 \\
0.20\end{array}$ & - & & & & & & 090 & 43 & \\
\hline & No. 2 & & 92 & & 0.19 & 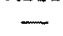 & 0. & & & 0.0 & & & .50 & \\
\hline & & (fff) & .95 & 15.6 & 0.20 & 0.110 & & & & & & & & \\
\hline 10 & $N$ & $\begin{array}{l}R-f \\
(f f o r\end{array}$ & .71 & & 0.17 & - & & & & & & & 14 & \\
\hline & 1) & & & 13.5 & & $\begin{array}{l}0.099 \\
-\end{array}$ & & & & & & & & \\
\hline & & $(\mathrm{f}$ & 2.15 & \begin{tabular}{|l|l}
17.2 \\
\end{tabular} & & 0.104 & & & & & & & & \\
\hline & & & & , & 0.20 & - & & & & & & & ia & \\
\hline & & (fff) & & 15.6 & & & & & & & & & & \\
\hline & 3 & $\begin{array}{l}\begin{array}{l}R-f \\
(\mathrm{fff})\end{array}\end{array}$ & & & 10 & & & & & & & & .47 & \\
\hline
\end{tabular}

side, and on the amount of yakriton on the other, as shown in Fig. 1 and Fig. 2. The duration of the insulin hypoglycemia will be shortened by the use of yakriton which will again be seen from Fig. 1 and Fig. 2, especially from Fig. 1. This shows that a larger amount (a larger number of units) of yakriton will shorten the time of the hypoglycemic action of insulin more remarkably. And the relationship 
Fig. 1. Blood sugar curve caused by intravenous injection of insulin under the infiuence of yakriton in an amount of 4 R.A.U. (in the case of No. 4 in Table II).

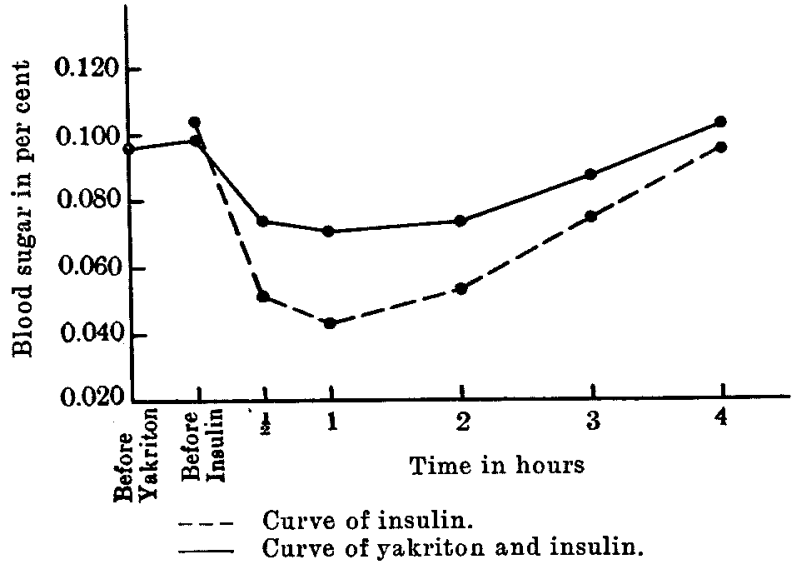

Fig. 2. Blood sugar curve caused by intravenous injection of insulin under the influence of yakriton in an amount of 8 R.A.U. (in the case of No. 4 in Table III)

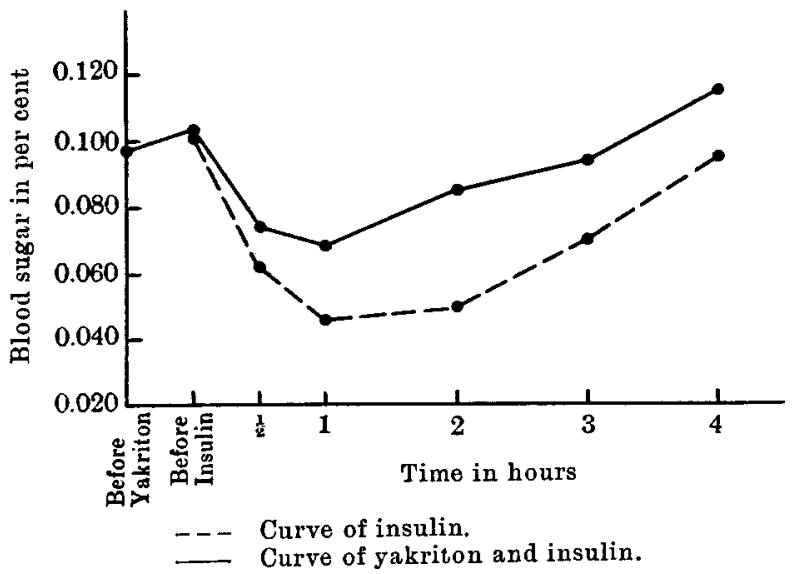

between the preventative effect of yakriton upon the hypoglycemic action of insulin and the intervals between the administration of the two hormones will be illustrated in the accompanying diagrams (Fig. 3\& Fig.4). Further report as to the relationship between the preventative effect of yakriton upon the hypoglycemic action of insulin and the amount of yakriton will be published in the near future in this journal.

By the way, the hypoglycemic action of insulin is influenced by the classes of detoxicating liver power, $\left.{ }^{6}\right)$ because the differences of hypoglycemic index ${ }^{7)}$ produced with yakriton are larger in most cases of $f$-classed animals than in $b$-classed animals (Cf. Tables I, II, III and IV).

6) A. S ato and H. S akurada, Tohoku J. Exp. Med., 1927, 8, 347.

7) Cf. Footnote. p. 528. 
Fig. 3. Relation between the preventing effect of yakriton on insulin-hypoglycemia and the interval between the administration of yakriton and insulin. In the case of 4 R.A.U. of yakriton.

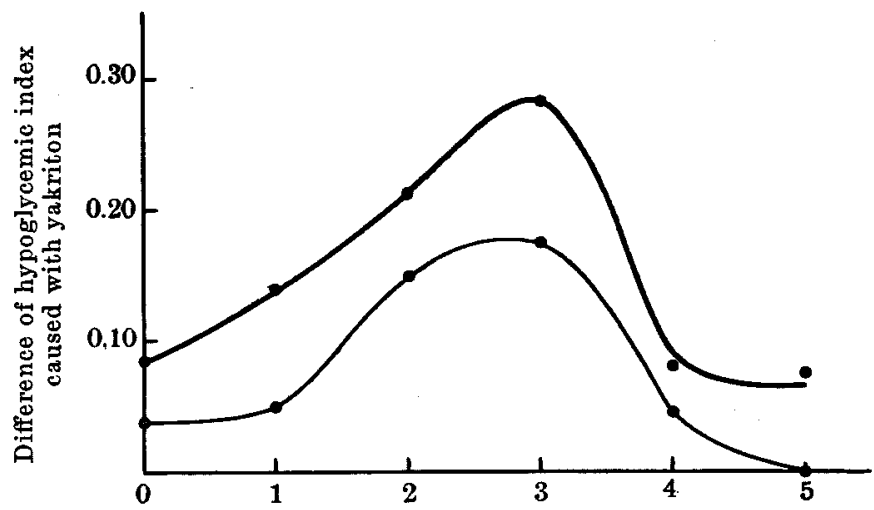

Time in hours between the administration of yakriton and insulin in the case of $b$-classed animals.

Fig. 4. Relation between the preventing effect of yakriton on insulin-hypoglycemia and the interval between the administration of yakriton and insulin. In the case of 8 R.A.U. of yakriton.

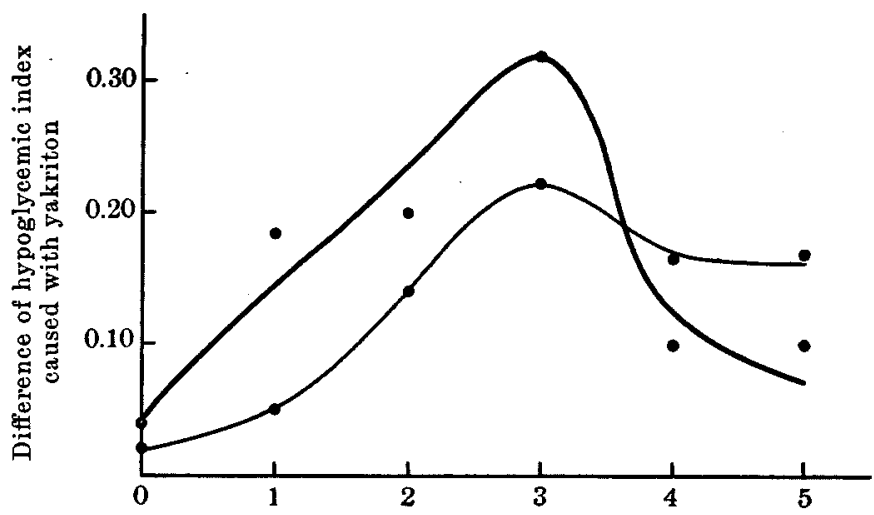

Time in hours between the administration of yakriton and insulin

$\longrightarrow$ in the case of $b$-classed animals.

in the case of $f$-classed animals.

\section{Discussion.}

As the results of our experiments have definitely shown, the hypoglycemic action of insulin is decreased or prevented by yakriton. 
An injection of yakriton even in such an amount as of 4 R.A.U. or 8 R.A.U. if used with insulin simultaneously exerts a remarkable effect on the hypoglycemic action of insulin. The effect will be very remarkable, if it is used 3 hours previous to the use of insulin. In other words, yakriton shows an inhibiting effect upon the hypoglycemic action of insulin, differing in strength according to how much earlier it is used than the latter hormone. These results prove the existence of a close relationship between the hypoglycemic action of insulin and the liver, and it is not unreasonable to think that yakriton physiologically and constantly produced from the normal liver in the body is always counteracting the otherwise harmfully hypoglycemic action of insulin, thus contributing to the keeping of the normal blood level. Such an assumption is to be considered as reasonable also from the study of literature. Observations are made by Mann and Magath, ${ }^{8}$ who state on the basis of their experiments that the blood sugar can not be maintained normally when the liver is totally removed and that the return to normal of the reduced blood sugar following insulin is greatly retarded when the liver is partially removed, but that the liver is certainly not necessary for the hypoglycemic action of insulin. Hetén $\mathrm{i}^{\mathrm{i}^{9}}$ also observed that the return to normal of the blood sugar following the intravenous administration of insulin was retarded in liver patients. Loew $i^{10)}$ also claims to have isolated a hormone from the liver which is antagnonistic to insulin. He calls this substance glykämin. On the other hand, other investigators of insulin have found that the presence of the liver is very necessary for the hypoglycemic action of insulin. Markowitz, Mann and Bollmann ${ }^{11}$ suggested, on the basis of their experiments, that perhaps the liver plays a major part in the action of insulin in intact animals and that the action of insulin on carbohydrate in intact animals is possibly dependent on a third and yet unknown factor. In $1932 \mathrm{Himsworth}{ }^{12)}$ concluded, comparing the content of the capillary blood sugar and that of the venous blood sugar after the administration of glucose, that insulin was secreted by the pancreas as an inactive material which would require an activation by some unknown substance for which

8) Frank C. Mann and Thomas B. Magath, Amer. J, of Physiol., 1923, 65, 403.

9) Geza Hete nyi, Deutsch. Med. Wochenschr., 1926, 1119.

10) L oe wi, 0., Klin. Wochenschr., 1927, 856.

11) J. Markowitz, Frank C. Mann and Jesse L. Bollmann, Am. J. Physiol, $1929,87,566$.

12) H. P. Hims worth Lancet, 1932, 223, 935. 
they tentatively propose the name of insulin kinase and also suggested that the insulin kinase might be produced in the liver. Though these opinions do not seem to concern us directly, it will be seen that the liver will play a certain part in the hypoglycemic action of insulin. We have shown that yakriton, the detoxicating hormone isolated from the liver by Prof. A. Sato, counteracts the action of insulin. And if the liver plays a rôle in insulin action, yakriton will be at least one of the most important principles participating in the rôle.

\section{Conclusions.}

Yakriton, the detoxicating hormone of the liver, counteracts hypoglycemic action of insulin, specially when it is used 3 hours previous to the administration of insulin.

This paper of $\mathrm{T}$ a k a mats $\mathrm{u}$ is the first original publication to deal with the relation between yakriton and another hormone. I shall take up this problem in a later publication, because $I$ have once touched upon this problem in a previous paper of mine (Cf. Tohoku J. Exp. Med., 1929, 13, 507).

Prof. A. Sato.

* "Hyperglykämischer Index" (Cf. N. F ucci, Kongr. Zent. Bl. 1933, 68, 151) $=\frac{\text { Maximum blood sugar after adrenalin }}{\text { Blood sugar before adrenaline }}$ I used " hypoglykemic index" for $\frac{\text { Minimum blood }}{\text { Blood sugar }}$ sugar after insulin 